\title{
Effect of Power Grasping on Muscle Activity of Trunk during One Leg Stance
}

\author{
Yong-Soo Kong, Yoon-Tae Hwang \\ Department of Physical Therapy, Gangneung Yeongdong College, Gangneung, Korea
}

Purpose: This study investigated the effects of trunk muscle activity with power grasping during one leg stance.

Methods: Twenty-eight subjects participated in this study. Subjects were divided into two groups, one that performed power grasping, and another that did not. An investigator measured the activities of a subject's trunk muscle such as internal oblique (I0), external oblique (EO), erector spinae (ES), and gluteus medius (GM) while a subject was doing one leg stance.

Results: An independent t-test was used to analyze trunk muscle activities with power grasping during one leg stance between the experimental group and the control group. Only the EO activity differed significantly between groups $(p<0.05)$.

Conclusion: The results indicate that one leg stance with power grasping affected trunk muscle activity. Therefore, this is a useful method for providing lumbar spine stability.

Keywords: One leg stance, Power grasping, Low back pain

\section{서 론}

요통은 여러 구조적, 심리적 요인들이 관련되어 있어 원인을 정확히 규명할 수 없는 경우도 많지만 주된 원인으로 척추의 변형과 근 골격 계 질환으로 인한 생체 역학적 요인, 생활환경의 변화로 인한 사회적 요인, 스트레스나 긴장과 같은 심리적 요인, 흡연이나 고도의 비만, 신 장장애 등의 기타 원인이 있다.' 요통환자는 신체 전반적인 활동성이 감소되며, 장기적인 비 활동성과 불용으로 인하여 근 위축 및 근력저 하를 유발하여 다시 요통이 악화되고 이차적인 척추 손상 및 신체장 애를 유발하게 된다.2

O'Sullivan 등 3 은 요통 환자는 요부의 심부근육이 정상인에 비하여 약하고 불균형적일 뿐 아니라 고유수용성감각의 감소로 위치 감각능 력이 떨어져 결국 척추의 안정성에 문제가 발생하고 이는 요통의 재발 을 가져온다고 하였다. 뿐만 아니라 요통환자는 척추전방전위증, 추간 판탈출증, 천장관절증후군, 그리고 요부염좌와 같은 척추의 불안정성 을 가지고 있으며, 개인차나 병리적인 문제로 인하여 척추의 중립상태 를 벗어나 있다고 하였다. ${ }^{4}$ 이로 인하여 요추의 굽힘근과 폄근의 근력 을 약화시키며, ${ }^{5}$ 정상인에 비해 배가로근의 근력이 약하고 그 외에 척 추세움근 및 다른 복부근육들도 근력이 약하다고 하였다. ${ }^{6}$
이들 환자들에게서 운동조절(motor control)의 기능장애가 관찰되 었으며, 이들 요통환자를 위한 최적의 중재 전략에 관하여 임상가와 학자 간의 논쟁이 지속되고 있으며, 이러한 운동제어는 코어 안정을 말하고 요추주변의 기능적인 안정을 유지하는 근육조절이 필요하다 고 하였다. ${ }^{8}$ 최근 연구와 치료들은 이에 그치지 않고 체간의 안정성을 획득하여 예방 및 재발의 가능성을 감소하는 것에 더 많은 연구가 이 루어지고 있으며, 척주의 정렬과 자세, 체간의 안정성에 관여하는 소 단위 근육들에 초점을 두고 있다.9

허리 부분에서의 조직손상은 다른 조직에 연달아 영향을 미칠 수 있게 되는데 이로 인해 특정한 움직임을 수행하는데 어려움을 겪게 된다. ${ }^{10}$ 한발서기 자세는 일상생활에서 많이 요구되는 자세이고, 한발 서기 검사는 허리엉치부위의 안정성과 움직임의 질을 평가하기 위해 사용하고 있으며,"1 여러 가지 균형장애를 동반한 환자의 평가도구로 도 종종 사용된다. ${ }^{12}$ 요통환자의 경우 한발서기 검사시 정상인 보다 자세 안정성이 좋지 않다고 하였으며, 요통을 동반한 환자의 경우 우 세 하지(dominant leg)로 한발서기 검사를 하는 동안 상대적으로 안 정성이 유의하게 감소되어 있었다. ${ }^{13} S a k a m o t o$ 등 ${ }^{14}$ 은 한발서기 균형 능력이 떨어질수록 넘어짐의 위험이 증가하므로, 한발서기 균형 훈련 은 균형 능력을 향상시키고, 더 나아가 넘어짐의 위험도를 낮춘다고 
하였다. 정상적인 균형 조절은 감각계와 근 골격계의 복잡한 상호작 용으로 발생하며, 시각, 전정, 그리고 고유수용성감각의 정보입력이 중요한 역할을 한다. 또한, 균형이 소실되었을 경우 이러한 감각들은 신체 동요에 대한 균형을 바로 잡게 도와준다.15 이처럼 질병이나 외상 으로 인해 감각운동조절체계가 손상되거나 예기치 못한 헛디딤이나 충돌이 발생한 경우, 또는 불안정성을 느낄 때 한발 서기의 균형이 무 너지게 된다고 하였다.16 요통환자의 경우 요추 하부분절의 불안정성 과 흥추의 움직임 제한, 엉덩관절의 굽힘과 폄의 움직임 제한, 중간볼 기근 후방 섬유의 약화와 복근의 조절 장애로 인해 한발 서기 시 고 관절 주위근에 비효율적인 근육의 활동을 유발시킨다. ${ }^{77}$

이처럼 자세 조절은 인체의 무게 중심을 지지기반 위에서 유지하 는 끊임없는 과정이며, ${ }^{18}$ 자세 조절은 시각으로부터 받아들이는 서 있 거나 보행의 구성을 계획하는 외부자극의 과정과 선형이나 각도의 가속을 감지하는 전정기관과 자세나 인체 분절의 속도를 감지하는 체성감각을 통하여 중추 신경계에서 수행하는 지속적이고 비선형적 이며 복합적인 과정을 포함한다. ${ }^{19}$ 이와 같이 균형은 닫힌 운동 사슬 에 의해 유지되고 엉덩관절, 무릎, 발목의 전략적 움직임에 의한 반응 의 통합에 의해 유지되지만 하지의 구조적 운동 사슬이나 관절의 역 학적 안정성 결핍, 근력의 결핍으로 인해균형을 붕괴시킨다. ${ }^{20}$

악력은 물체에 힘을 전달하기 위한 엄지와 손가락들의 강압적인 활동이며, 환자의 악력이 손을 이용한 동작을 수행하는 능력을 결정 하기도 한다. 또한 정상적인 악력은 일상생활동작을 하는데 중요한 요소이다. ${ }^{21}$ 악력은 정형외과, 재활의학 및 산업의학에서 어깨 기능의 정량적 지표와 손과 손목의 기능 평가지표 및 재활치료 프로그램의 기준으로 활용되고 있으며,2 최근 악력의 정도가 심장질환, 뇌졸중, 폐렴 등의 질병 발생률뿐만 아니라 사망률과도 상관관계가 있는 것 으로 확인되어 건강상태, 신체노화 정도의 평가 등 건강지표로도 널 리 활용되고 있다. ${ }^{23.24}$ 선행 연구에서는 악력을 이용하여 주로 상지와 손 어깨의 기능 그리고 노인의 근력에 대하여 대부분 연구를 하였으 며 체간의 근육에 대한 연구는 거의 없는 실정이다.

한발서기 능력은 보행 시 균형 유지와 많은 연관이 있으며, 특히 한 발서기 균형은 향후 중요한 운동프로그램이나 재활의 초점의 대상 이 된다. 또한 자세 균형을 위하여 한발 서기 자세가 골반부 근육의 검사인 코어안정화 근육의 질적 양적 검사가 될 수 있다고 하였다. ${ }^{10}$

이에 본 연구는 일반인을 대상으로 하여 한발서기 자세에서 악력 을 제공하여 체간근육의 근 활성도를 측정하고자 한다. 정적 자세로 균형을 유지하는 한발서기 자세에서 악력을 제공하여 골반과 체간 의 움직임에 영향을 주는 근육들의 근 활성도를 분석함으로써 한발 서기 자세가 균형과 체간에 영향을 주는 기초자료를 제공하는데 그 목적이 있다. 본 연구의 가설은 각 근육의 근 활성도에는 차이가 없을 것이다라고 설정하고 본 연구를 실시하였다.

\section{연구 방법}

\section{1. 연구대상}

본 연구는 강원도에 소재한 Y대학교에 재학 중인 성인 남, 여 28 (남: 11 명, 여: 17명)명을 대상으로 실험을 진행 하였다. 실험을 실시하기 전 연구의 목적과 방법에 대하여 설명을 들은 후 헬싱키 선언의 윤리표 준에 따라 동의서를 작성한 후 본 연구를 실시하였다. 선정된 대상자 는 연구자의 임의 방식대로 무작위로 두 그룹으로 설정하였으며 악 력을 제공하는 실험군과 악력을 제공하지 않은 대조군으로 나누었 다. 대상자 중 균형을 방해하는 신경학적 손상이나 전정기관에 문제 가 있는 자, 프로그램을 수행할 수 없는 자, 척추수술을 한 자는 대상 자에서 제외를 하였다.

\section{2. 실험방법}

한발서기 자세는 실험자가 “다리를 들어 올리세요”라는 구령과 함께 대상자는 눈을 뜬 상태로 우세다리(dominant leg)로 지지 하였고, 비 우세측 다리를 들어 고관절과 슬관절을 $90^{\circ}$ 구부리게 하였다. 대상자 는 정면을 응시하게 하였고 양손은 자연스럽게 차렷 자세를 취하였 다. 실험군에게는 한발서기 자세에서 3 초 후 대상자에게 "볼을 꽉 잡 으세요”라는 구령을 하였으며, 치료용볼은 우세손(dominant hand)으 로 잡게 하였다. 대조군 또한 한발서기 자세를 15 초간 유지 하였다.

\section{3. 측정도구}

손의 악력을 사용하기 위한 도구로는 손의 저항기구로 사용하는 것 으로 hand exercise라 불리는 치료용 볼(Sammons preston, USA)지름 5 $\mathrm{cm}$, 둘레 $15.5 \mathrm{~cm}$ 인 그린색을 사용하였다. 그리고 체간근육의 근활성 도를 보기 위하여 무선근전도(telemyo 2400T-G2, Noraxon, USA)를 이 용하였으며, 전극은 $\mathrm{Ag} / \mathrm{Ag}-\mathrm{Cl}$ (Biopac, diameter $2 \mathrm{~cm}$ )를 사용하여 측 정하였다. 표면 근전도 시스템에서 디지털 처리된 표면 근전도 신호 는 개인용 컴퓨터에서 MR-XP 프로그램을 이용해 처리하였다. 표면 근전도 신호의 표본 추출률(sampling rate)은 $1,024 \mathrm{~Hz}$ 이였으며, 20$500 \mathrm{~Hz}$ 대역필터(band pass filter)와 $60 \mathrm{~Hz}$ 로 노치필터(notch filter)를 사용하였다. 수집된 신호는 완파정류(full wave rectification)한 후, root mean square (RMS)로 처리하여 분석하였다. 전극부착부위의 피부저 항 감소를 위해 가는 사포질을 3-4회 한 후, 탈지면에 소독용 알코올 을 적셔 피부 표면을 깨끗이 닦고 전극을 부착하였으며, 전극은 근섬 유의 주행 방향에 따라 부착하였으며, 접지 전극은 전상장골극 (ASIS)위에 부착하였다.

각 자세에 따른 동작은 15 초 동안 실시하였으며, 시작과 끝부분에 서 오차를 줄이기 위해 처음 4 초와 마지막 4 초를 제외한 7 초 동안의 측정값을 사용하여 근활성도를 분석하였다. 모든 동작 시 근전도 측 
정은 2회 반복 측정하여 평균값을 산출하였다. 한발서기 자세에 따 른 근활성도를 측정하기 위하여 4 개의 근육에 전극을 부착하여 측 정하였다. 배속빗근(internal oblique, IO), 배꼽선과 위앞엉덩뼈가시의 중간지점, 배바깥빗근(external oblique, EO), 배꼽에서 외측 $15 \mathrm{~cm}$ 지점, 척추세움근(erector spinae, $\mathrm{ES}$ ), $\mathrm{L} 2$ 극돌기로부터 외측 $2 \mathrm{~cm}$ 지점, 중간 볼기근; 장골능과 대전사 사이의 $1 / 2$ 지점을 선택하였고, ${ }^{25}$ 실험 대상 자들의 우세측 근육(dominant)에 부착 하였다.

각 근육의 활동전위를 표준화하기 위하여 최대 등척성 수축(maximal voluntary isometric contraction, MVIC)을 사용하였다. 최대 등척 성 수축을 위한 맨손 근력자세는 Kendall 등 26 의 방법을 사용하였다.

\section{3. 자료분석}

수집된 자료는 SPSS 18 PASW Statistics를 이용하여 통계처리를 하였 으며, 대상자의 일반적 특성을 보기 위하여 기술통계를 하였다. 실험 군과 대조군의 그룹 간 근활성도 비교를 위하여 독립표본 t-검정을 하였으며, 통계적 유의수준은 $\mathrm{p}<0.05$ 로 하였다.

\section{연구 결과}

\section{1. 대상자의 일반적 특성}

악력을 제공한 실험군의 평균 나이는 $21.66 \pm 1.11$ 세, 평균 키는 167.01 $\pm 8.57 \mathrm{~cm}$, 평균 체중은 $64.73 \pm 11.49 \mathrm{~kg}$ 였고, 악력을 제공하지 않은 대 조군의 평균 나이는 $21.92 \pm 1.18$ 세, 평균 키는 $166.53 \pm 7.28 \mathrm{~cm}$, 평균 체 중은 $65.01 \pm 11.73 \mathrm{~kg}$ 였다(Table 1$)$.

\section{2. 악력에 따른 근 활성도 비교}

실험군과 대조군의 악력에 따른 근 활성도를 보기 위하여 독립표본 $\mathrm{t}$-검정을 실시 한 결과 배속빗근, 척추세움근, 중간볼기근은 대조군 에 비해 실험군에서 더 작은 근 활성도를 보였으나 그룹 간 유의한차 이를 보이지 않았다. 하지만 배바깥빗근은 실험군에서 더 작은 근 활 성도를 보였고 그룹 간 유의한차이를 보였다 $(\mathrm{p}<0.05)$ (Table 2).

\section{고 찰}

한발서기 자세는 체간근육을 안정화 하기 위한 운동 중 하나이며 균

Table 1. General characteristics of subjects

\begin{tabular}{lcc}
\hline & Control group $(n=13)$ & Experimental group $(n=15)$ \\
\hline Age $(\mathrm{yr})$ & $21.92 \pm 1.18$ & $21.66 \pm 1.11$ \\
Height $(\mathrm{cm})$ & $166.53 \pm 7.28$ & $167.01 \pm 8.57$ \\
Weight $(\mathrm{kg})$ & $65.01 \pm 11.73$ & $64.73 \pm 11.49$ \\
\hline
\end{tabular}

Values are means \pm standard deviation.
형을 측정하기 위해 임상에서도 많이 사용되어지는 검사법이다. 요 통환자의 경우 한발서기 검사 시 정상인 보다 자세 안정성이 좋지 않 다고 하였는데 이것은 요통환자의 한발서기 자세에서 요부와 골반의 근력, 협응 및 근육의 효과적인 상호작용이 손상되어 자세균형에 방 해를 받는 것이라고 하였다.27

본 연구에서는 일반인을 대상으로 한발서기 자세에서 악력을 제 공하였을 때 체간근의 근 활성도에 어떠한 영향을 미치는지를 알아 보고자 본 연구를 실시하였다. 연구결과 한발서기 자세에서 배바깥 빗근의 근 활성도는 그룹 간 유의한 차이를 보였으며, 배속빗근, 척추 세움근, 그리고 큰볼기근의 근 활성도는 그룹 간 유의한 차이를 보이 지 않았다. 전반적으로 대조군보다 악력을 제공한 실험군에서 근 활 성도가감소됨을 알수 있었다.

$\mathrm{Lee}$ 와 $\mathrm{Ro}^{28}$ 의 연구에서 손을 사용하는 것은 운동조절과 안정성에 관여한다고 보고하였는데 손에서 일정 정도의 강한 압력을 지속하 게 되면 연합반응(association reaction)에 의하여 체간의 동시수축도 유발되어 안정성이 제공되어진다고 하였다. 본 연구에서도 한발서기 자세에서 악력을 제공할 때 실험군에서 체간의 안정성이 더욱 향상 됨을 알수 있었다.

Cynn 등 29 은 요추 골반부(lumbopelvic)의 근육들의 상호작용에 의 한 요추의 안정성 증가는 하지가 움직이는 동안 허리네모근의 근 활 동을 감소시키는 반면, 중간볼기근의 근 활동을 증가시킨다고 하였 으며, Souza 등 30 은 빗근은 허리의 회전을 막아 척추의 안정성 유지에 효과적인 근육이라 하였다. 본 연구에서도 한발서기 자세에서 악력 을 제공한 결과 배바깥빗근, 배속빗근, 척추세움근, 그리고 큰볼기근 의 근 활성도가 대조군보다 감소 되었으며, 특히 중간볼기근의 근 활 성도가 높았으나 유의한 차이는 보이지 않았다. 이러한 것은 한발서 기 자세에서 하지를 지지하는 동안 중간볼기근의 역할이 우세하여 다른 근육들보다 근 활성도가 증가된 것으로 생각되어진다. 하지만 악력을 제공하였을 때 중간볼기근의 안정성은 제공되어졌지만 그 영 향은 크지 않았다. 그리고 배속빗근, 척추세움근, 배바깥빗근은 악력 을 제공하였을 때 근 활성도가 감소되었으며 특히 배바깥빗근의 근 활성도가 가장 크게 감소를 하였다. 이것은 악력을 제공함으로써 상 지와 연결된 체간의 동시수축을 유발하여 연합반응의 일환으로 안

Table 2. Comparison of muscle activities according to power grasping (unit: \% MVIC)

\begin{tabular}{lrccc}
\hline & Control group & Experimental group & $\mathrm{t}$ & $\mathrm{p}$ \\
\hline IO & $13.57 \pm 13.36$ & $10.58 \pm 4.83$ & 0.808 & 0.426 \\
EO & $17.96 \pm 13.43$ & $9.38 \pm 5.10$ & 2.297 & $0.031^{*}$ \\
ES & $7.78 \pm 10.51$ & $4.87 \pm 3.06$ & 1.026 & 0.314 \\
GM & $30.69 \pm 21.72$ & $26.26 \pm 15.68$ & 0.618 & 0.547 \\
\hline
\end{tabular}

${ }^{*} \mathrm{p}<0.05$, IO: internal oblique, EO: external oblique, ES: erector spinae, GM: gluteus medius. 
정성이 제공되어져 근 활성도가 감소된 것으로 사료된다. 한발서기 자세의 경우 균형을 제어하는데 어려움이 있으며, 지지 기저면이 좁기 때문에 좀 더 정교한 근육의 협응력이 필요한 자세이 다. 따라서 한발서기 자세와 같은 정적인 동작에서 손에 악력을 제공 하였을 때 체간근육의 근 활성도에 영향을 미친다는 것을 알 수 있었 다. 특히 대근육인 배바깥빗근의 근 활성도가 많이 향상이 되었다.

결론적으로 한발서기 자세에서 악력을 제공할 때 배속빗근, 배바 깥빗근, 척추세움근, 그리고 중간볼기근의 근 활성도가 감소되었다 는 것은 악력을 제공하는 것이 기존의 한발서기 자세보다 척추의 안 정성에 있어 조금 더 영향을 준다는 것으로 해석할 수 있다.

본 연구의 제한점은 연구대상자가 요통환자가 아닌 일반인을 대상 으로 하였다는 점과 샘플의 수가 적어 일반화하여 해석하기에는 어 려움이 있다. 그리고 발목관절 주변 근육의 근 활성도를 고려하지 못 한 점도 있다. 향후 이와 같은 내용의 연구를 요통환자를 대상으로 좀 더 큰 표본을 대상으로 그리고 균형과 고유수용성 감각을 연계한 후속연구가 필요할 것으로 사료된다.

\section{참고문헌}

1. Burton AK, Balague F, Cardon G et al. European guidelines for prevention in low back pain. Euro Spine J. 2006;15(2):136-68.

2. Kader DF, Wardlaw D, Smith FW. Correlation between the mri changes in the lumbar multifidus muscles and leg pain. Clin Radiol. 2000;55(2): 145-9.

3. O'sullivan PB, Burnett A, Floyd AN. Lumbar repositioning deficit in a specific low back pain population. Spine. 2003;28(10):1074-9.

4. Kong YS, Jang GU, Park S. The effects of prone bridge exercise on the oswestry disability index and proprioception of patients with chronic low back pain. J Phys Ther Sci. 2015;27(9):2749-52.

5. Johannsen F, Remvig L, Kryger P et al. Exercises for chronic low back pain: a clinical trial. J Orthop Sports Phys Ther. 1995;22(2):52-9.

6. Hodges PW, Richardson CA. Inefficient muscular stabilization of the lumbar spine associated with low back pain. A motor control evaluation of transversus abdominis. Spine. 1996;21(22):2640-50.

7. Brumitt J, Matheson JW, Meira EP. Core stabilization exercise prescription, part i: current concepts in assessment and intervention. Sports Health. 2013;5(6):504-9.

8. Akuthota V, Scott F, Nadler D. Focused review core strengthening. Arch Phys Med Rehabil. 2004:86-92.

9. Norris CM. Functional load abdominal training: part 1. J Bodyw Mov Ther. 1999;3(3):150-8.

10. Page P, Frank CC, Ladner R. Assessment and treatment of muscle imbalance the janda approch. Seoul, Yeongmunsa, 2012;15-230.

11. Sahrmann SA. Diagnosis and treatment of movement impairment syndrome. St Louis, Mosby, 2002:51-118.
12. Bohannon RW, Larkin PA, Cook AC et al. Decrease in timed balance test scores with aging. Phys Ther. 1984;64(7):1067-70.

13. Jo HJ, Song AY, Lee KJ et al. A kinematic analysis of relative stability of the lower extremities between subjects with and without chronic low back pain. Eur Spine J. 2011;20(8):1297-303.

14. Sakamoto K, Nakamura T, Hagino H et al. Effects of unipedal standing balance exercise on the prevention of falls and hip fracture among clinically defined high-risk elderly individuals: a randomized controlled trial. J Orthop Sci. 2006;11(5):467-72.

15. Carr J, Shepherd R. Neurological rehabilitation: optimizing motor performance. 2nd ed. Edinburgh,Churchill Livingstone, 2010:163-6.

16. Won JI. Effects of using a mobile phone on postural control. Phys Ther Korea. 2012;19(3):61-71.

17. Albasini AA. Chronic low back pain and leg pain management: the mcconnell approach. Course book. Netherland, Rotterdam, International congress of ifomt, 2008.

18. Yaggie JA, McGregor SJ. Effects of isokinetic ankle fatigue on the maintenance of balance and posturallimits. Arch Phys Med Rehabil. 2002; 83(2):224-8.

19. Blaszczyk JW, Bacik B, Juras G. Clinical assessment of postural stability. J Mech Med Biol. 2003;3(2):135-44.

20. Riemann BL, Myers JB, Lephart SM. Sensori motor system measurement techniques. J Athl Train. 2002;37:85-98.

21. Smith LK, Weiss EL, Lehmkuhl LD. Brunnstrum's clinical kinesiology, 5th ed. Philadelphia, FA Davis Co, 1996.

22. Schreuders TA, Roebroeck M, Van DK et al. Strength of the intrinsic muscles of the hand measured with a hand-held dynamometer: reliability in patients with ulnar and median nerve paralysis. J Hand Surg Br. 2000;25:560-5.

23. Hideo $S$. Grip strength predicts causes-specific mortality in middle age and elderly persons. Am J Med. 2007;120(4):337-42.

24. Chung JY, Lee JW, Im JY et al. Hand grip power is independenty associated with physical function in community dwelling elderly. Korean J Clin Geri. 2010;11(4):315-23.

25. Carm JR, Kasman GS, Holtz J. Introduction to surface electromyography. Gaithersburg, Aspen, 1998:360-74.

26. Kendall FP, McCreary EK, Provance PG et al. Muscles: testing and function with posture and pain. 5th ed. Philadelphia, Lippincott Williams \& Wilkins, 2005.

27. Luoto S, Aalto H, Taimela $S$ et al. One-footed and externally disturbed two-footed postural control in patients with chronic low back pain and healthy control subjects. A controlled study with follow-up. Spine. 1998; 23(19):2081-9.

28. Lee DH, Ro HL. The effects of increase in balance ability to one leg support exercises for adults using empty bottle. Neurotherapy. 2013;17:1-5.

29. Cynn HS, Oh JS, Kwon OY et al. Effects of lumbar stabilization using a pressure biofeedback unit on muscle activity and lateral pelvic tilt during hip abduction in sidelying. Arch Phys Med Rehabil. 2006;87(11):1454-8.

30. Sauza GM, backer LL, Powers CM. Electromyograpic activity of selected trunk muscles during dynamic spine stabilization exercises. Arch Phys Med Rehabil. 2001;82(11):1551-7. 